\title{
EBV-positive diffuse large B-cell lymphoma of the elderly with dual genotype and aberrant TIA-1 expression: a case report and review of literature
}

\author{
Tawatchai Pongpruttipan • Jitsupa Treetipsatit • Kanchana Amornpichetkul • \\ Tanawan Kummalue • Anchalee Chuphrom • Archrob Khuhapinant • \\ Noppadol Siritanaratkul • Sanya Sukpanichnant
}

Received: 13 February 2010 / Accepted: 10 June 2010/Published online: 29 June 2010

(C) Springer-Verlag 2010

\begin{abstract}
B-cell lymphomas generally do not express T-cell intracellular antigen-1 (TIA-1), a cytotoxic granuleassociated protein. We report a case of EBV-positive diffuse large B-cell lymphoma (DLBCL) of the elderly with aberrant expression of TIA-1. The patient was an 84-year-old man with a history of progressively enlarged left parotid mass and mild facial paresis for 2 months. The incisional biopsy revealed sheets of medium to large lymphoma cells with focal angiocentricity and extensive tumor necrosis; only a few scattered small lymphocytes were noted among the lymphoma cells. Immunohistochemistry in formalin-fixed paraffin-embedded tissue demonstrated that the lymphoma cells marked with CD20, CD30, CD45 (focal), CD79a, BCL2 (focal and weak), PAX5, Oct2, BOB.1, IRF4/MUM1, EBV-LMP1, and TIA-1, but they did not mark with CD3, CD4, CD5, CD7, CD8, CD10, CD15, CD23, CD56, CD57, CD138, kappa and lambda immunoglobulin light chains, BCL6, $\beta F 1$, granzyme $\mathrm{B}$, or perforin. The aberrant TIA-1
\end{abstract}

T. Pongpruttipan $(\bowtie) \cdot$ J. Treetipsatit $\cdot$ K. Amornpichetkul $\cdot$

S. Sukpanichnant

Department of Pathology, Faculty of Medicine Siriraj Hospital,

Mahidol University,

Bangkok 10700, Thailand

e-mail: watpptp@yahoo.com

T. Kummalue $\cdot$ A. Chuphrom

Department of Clinical Pathology, Faculty of Medicine Siriraj

Hospital, Mahidol University,

Bangkok, Thailand

A. Khuhapinant $\cdot$ N. Siritanaratkul

Division of Hematology, Department of Medicine,

Faculty of Medicine Siriraj Hospital, Mahidol University,

Bangkok, Thailand expression was then confirmed by two different autostainers. EBV-encoded RNA (EBER) in situ hybridization was positive in the lymphoma cells. Gel electrophoresis for immunoglobulin heavy chain $(\operatorname{IgH})$ and T-cell receptor (TCR) gene rearrangements revealed no definite clonal band, but fluorescence capillary electrophoresis demonstrated positive results for both IgH and TCR genes. Finally, we concluded this case as an EBV-positive DLBCL of the elderly with dual genotype (rearrangements of both $\operatorname{IgH}$ and TCR genes) and aberrant TIA-1 protein expression.

Keywords Diffuse large B-cell lymphoma EBV. TIA-1 . Cytotoxic protein - Immunoglobulin heavy chain gene . T-cell receptor gene

\section{Introduction}

Diffuse large B-cell lymphoma (DLBCL) is a type of mature B-cell neoplasm in the WHO classification (2008), and it is the most common lymphoma worldwide [1]. It is also the most common lymphoma in Thailand $[2,3]$. It commonly occurs in either nodal or extranodal sites. EBVpositive DLBCL of the elderly is an EBV-associated DLBCL subtype, occurs in more than 50-year-old patients, and usually found in extranodal sites [1].

TIA-1 protein was identified by Anderson et al. [4] as a cytotoxic granule-associated protein, involving in apoptosis-promoting protein [5]. It has been found in the cytoplasm of both normal and neoplastic cytotoxic T-cells and NK-cells $[1,4,6]$. However, TIA-1 expression is not generally found in normal and neoplastic B-cells.

Although almost all cases of DLBCL show immunoglobulin heavy chain $(\mathrm{IgH})$ gene rearrangement, demon- 
strated by molecular genetic techniques [1, 7-9], but bigenotypic DLBCL, which has both immunoglobulin heavy chain (IgH) and T-cell receptor (TCR) gene rearrangement (DLBCL with dual genotype), is not uncommon $[7,8,10]$.

We report a case of EBV-positive DLBCL of the elderly with dual genotype and aberrant TIA-1 expression.

\section{Case history}

An 84-year-old man initially presented with a progressively enlarged left parotid mass, local pain, and low-grade fever for 2 months. He was previously healthy and did not have any history of chronic inflammation in this area. Physical examination revealed a left parotid mass with mild ipsilateral facial paresis. Fine needle aspiration of the mass revealed only some inflammatory cells with necrotic debris. Then, the patient was treated as parotid abscess. However, the clinical signs and symptoms were not improved; the mass still progressively enlarged, and left facial paresis gradually deteriorated. Computerized tomography (CT) scan revealed a well-circumscribed parotid mass, $7 \mathrm{~cm}$ in diameter, with central liquefaction, involving both superficial and deep lobes; no regional lymphadenopathy was noted. Due to there being no clinical improvement at patient follow-up, an incisional biopsy of the mass was then performed for histopathologic diagnosis.

\section{Materials and methods}

Histopathologic evaluation and immunohistochemical and in situ hybridization studies

The biopsy sample was processed in a technique for routine histopathology. Hematoxylin and eosin (H\&E) slides were reviewed. Immunohistochemistry from formalin-fixed paraffin-embedded tissue was performed by Bench-Mark ${ }^{\circledR}$ XT autostainer. In situ hybridization for EBV-encoded RNA (EBER), kappa, and lambda light chain mRNA were also performed in the same automated machine. After the unusual expression of TIA-1 (Biocare), the test was simultaneously repeated by both BenchMark $^{\circledR}$ XT (Roche Diagnostic) and Bond MAX ${ }^{\circledR}$ (Leica) autostainers.

\section{Molecular genetic studies}

Twenty serial $10-\mu \mathrm{m}$-thick sections from formalin-fixed paraffin-embedded tissue were obtained for molecular genetic study. In brief, tissue was extracted from paraffin by xylene and then followed by ethyl alcohol. QIAamp ${ }^{\circledR}$
DNA mini kit (Qiagen) was used for the DNA extraction. The DNA concentration was measured by Smartspect ${ }^{\circledR}$ (BIO-RAD).

The PCR primer sequences were designed following BIOMED-2 [11]. The numbers of forward/reverse primers for amplification of IgH, $\beta \mathrm{TCR}, \gamma \mathrm{TCR}$, and $\delta \mathrm{TCR}$ genes were $27 / 1,25 / 13,4 / 2$, and $7 / 5$, respectively. The $\operatorname{IgH}$, $\beta \mathrm{TCR}, \gamma \mathrm{TCR}$, and $\delta \mathrm{TCR}$ gene primers were arranged into five, three, two, and four groups, respectively. Each group of primers was used for DNA amplification in an individual test tube, in the thermal cycler (BIO-RAD). In brief, 800 $1,000 \mathrm{ng}$ genomic DNA was added up to a final reaction of $50 \mu$ l. After the initial hot start, using Faststart ${ }^{\circledR}$ (Roche Diagnostic) at $95^{\circ} \mathrm{C}$ for $7 \mathrm{~min}$, PCR-cycle program was denatured at $95^{\circ} \mathrm{C}$ for $45 \mathrm{~s}$, followed by annealing at $60^{\circ} \mathrm{C}$ for $45 \mathrm{~s}$, and extension at $72^{\circ} \mathrm{C}$ for $90 \mathrm{~s}$. The program was repeated for 34 cycles, and then a final extension was performed at $72^{\circ} \mathrm{C}$ for $10 \mathrm{~min}$.

For gel electrophoresis (heteroduplex analysis), the $20 \mu \mathrm{l}$ of PCR product was denatured at $95^{\circ} \mathrm{C}$ for $5 \mathrm{~min}$ and rapid random renatured at $4^{\circ} \mathrm{C}$ for $1 \mathrm{~h}$. Gel electrophoresis was performed in $6 \%$ polyacrylamide gel (non-denatured acrylamide gel, $16 \times 16 \times 0.1 \mathrm{~cm}$ ), using SE600 Ruby ${ }^{\circledR}$ (Amersham Bioscience), at room temperature, $110 \mathrm{~V}$, for $210 \mathrm{~min}$. The gel was stained by $0.5 \mu \mathrm{g} / \mathrm{ml}$ ethidium bromide and photographed under ultraviolet light using ChemiDoc $^{\mathrm{TM}}$ XRS System (BIO-RAD). Gel electrophoresis was performed in duplicate.

For fluorescence capillary electrophoresis (GeneScan ${ }^{\mathrm{TM}}$, Applied Biosystems), the PCR product was carried out by the conditions mentioned above, but with substitution of original primers by four-color fluorescence-labeled primers in each tube. The amplified fragments were analyzed by 3130 Genetic Analyzer ${ }^{\circledR}$ (Applied Bioscience), according to the manufacturer's protocol. In brief, each sample, containing $1 \mu \mathrm{l}$ of the PCR product, was mixed with $10.7 \mu \mathrm{l}$ of $\mathrm{Hi}-\mathrm{Di}{ }^{\mathrm{TM}}$ formamide and $0.3 \mu \mathrm{l}$ of $600 \mathrm{LIZ}^{\circledR}$ size standard (Applied bioscience). Samples were denatured at $95^{\circ} \mathrm{C}$ for $5 \mathrm{~min}$ and then immediately chilled on ice for 2 min. POP-4TM polymer solution (gel) (Applied Bioscience) was used for capillary electrophoresis. Intensity of the PCR products was analyzed by GeneMapper ${ }^{\circledR}$ software, version 3.2 (Applied Bioscience). Fluorescence capillary electrophoresis was performed in duplicate.

\section{Results}

The biopsy (see Fig. 1) revealed sheets of medium to large lymphoma cells with focal angiocentricity and extensive geographical necrosis. The obtained tissue included only skin and subcutaneous fat; no salivary tissue was obtained. The lymphoma cells showed homogeneous, medium to 
Fig. 1 DLBCL with cytotoxic granules. a At low magnification, scattered sheets of viable tumor cells (purple color) are noted on the background of extensive tumor necrosis (pink color). b Medium to large lymphoma cells infiltrate in the background of cell debris. A part of sweat gland is noted at the right upper corner $(\mathrm{H} \& \mathrm{E}$, $\times 400)$. c CD3-negative lymphoma cells with some scattered small reactive $\mathrm{CD} 3+\mathrm{T}$-cells. d CD20+ lymphoma cells (membranous staining). e Strongly positive TIA-1 (cytoplasmic staining) in lymphoma cells. f Positive EBER in situ hybridization (dark blue) in lymphoma cells
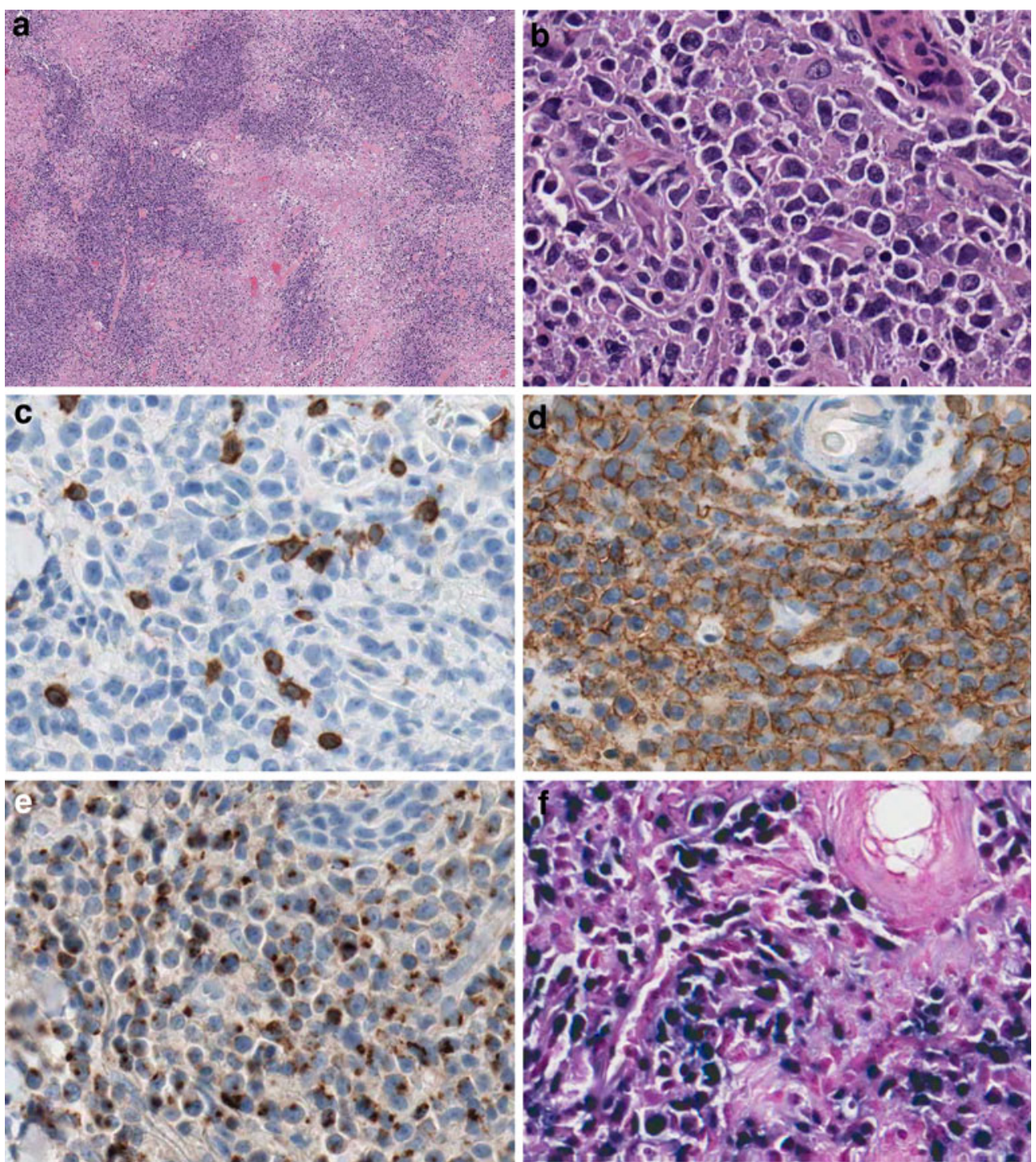

large, round to oval nuclei, vesicular nuclear chromatin, with a single nucleolus or a few small nucleoli, and a small amount of cytoplasm. A few scattered small lymphocytes were also noted among the lymphoma cells. There was no inflammatory background, polymorphous-looking area, anaplastic large cell, or Reed-Sternberg-liked cell, identified on all histological sections.

Immunohistochemistry demonstrated that the lymphoma cells marked with CD20, CD30 (70\% of tumor cells), CD45 (25\% of tumor cells), CD79a, BCL2 (focal and weak), PAX5, Oct2, BOB.1, IRF4/MUM1, EBV-LMP1, and TIA-1, but they did not mark with CD3, CD4, CD5, CD7, CD8, CD10, CD15, CD23, CD43, CD56, CD57, $\mathrm{CD} 138, \mathrm{BCL} 6, \beta \mathrm{F} 1$, granzyme $\mathrm{B}$, or perforin. TIA-1 was strongly and diffusely expressed by almost all of the lymphoma cells, with paranuclear dot and/or coarse cytoplasmic granular fashion. A few scattered small reactive T-cells $(\mathrm{CD} 3+)$ were noted. Proliferation index determined by Ki67 immunoperxidase was approximately $70 \%$. Less than $5 \%$ of the neoplastic cells marked with p53. Kappa and lambda immunoglobulin light chains were negative from both immunoperoxidase and in situ hybridization (for mRNA) techniques, respectively. EBER in situ hybridization showed diffuse positivity in the lymphoma cells, and the pattern of positivity was similar to the CD20-positive medium to large cells.

Based on gel and fluorescence capillary electrophoresis analyses, the patient's sample was performed in duplicate for detection of both $\mathrm{IgH}$ and TCR gene rearrangements. However, gel electrophoresis showed no definite clonal band of both IgH and TCR genes, whereas fluorescence capillary electrophoresis revealed positive results in both IgH and TCR genes (see Fig. 2). In detail, the IgH, $\beta$ TCR, and $\gamma$ TCR gene rearrangement was positive in two out of 
Fig. 2 Fluorescence capillary electrophoresis shows positive results of both $\operatorname{IgH}$ (prominent peak with asterisk in a) and TCR gene rearrangements (peak with asterisk in b). Note: The orange peaks with numberlabels are 600 LIZ $^{\circledR}$ sizestandard markers. IgH gene tube (a), contains six forward and one reverse primers, while TCR gene tube (b) contains two forward and 13 reverse primers. In each tube, four-color fluorescence-labeled primers produced up to four color peaks (other than the orange one). Therefore, difference in color represents different primer products and must be individually interpreted. However, the same color peak may be derived from different primer products, this because the numbers of primers exceed the numbers of fluorescence dyes a

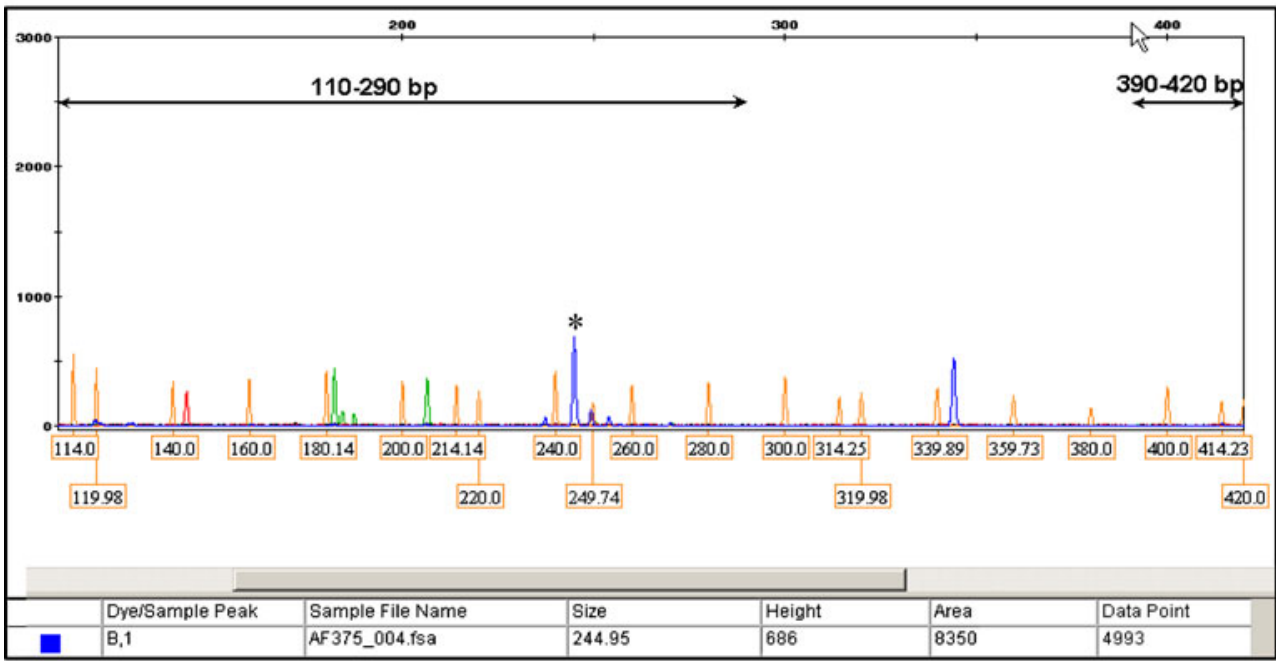

b

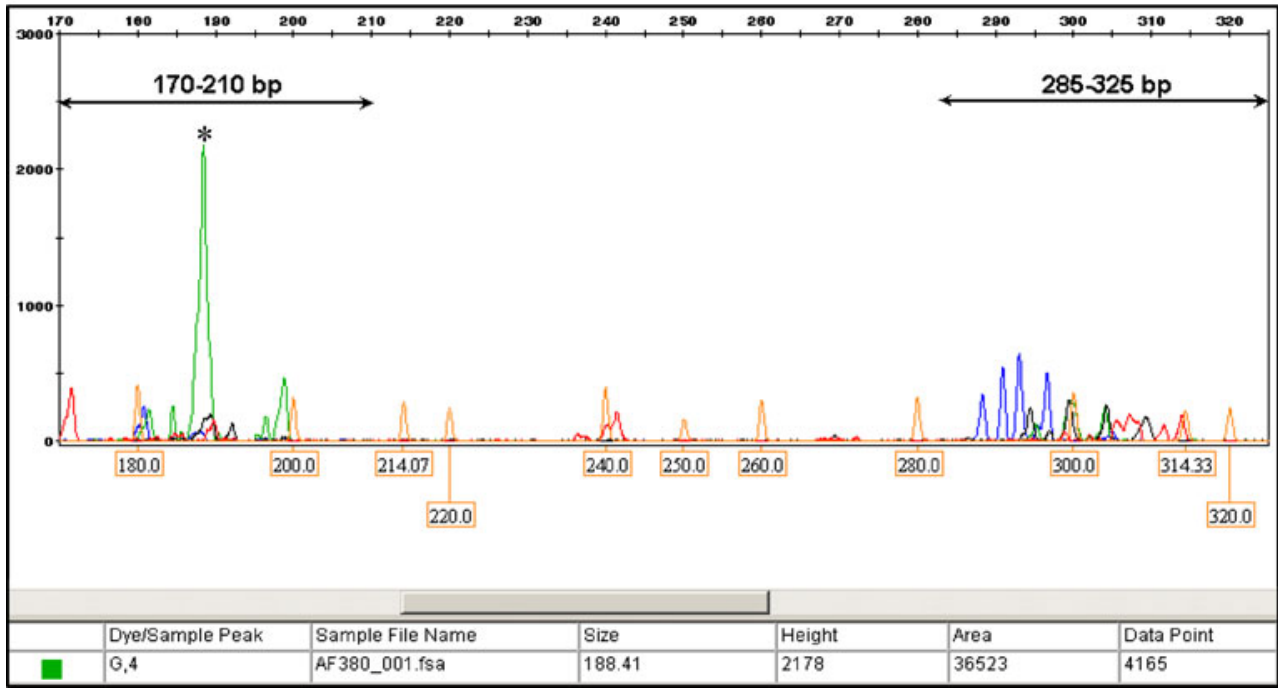

five, one out of three, and one out of two tubes, respectively. However, $\delta \mathrm{TCR}$ gene rearrangement was negative in all tests.

\section{Discussion}

This particular case showed diffuse growth pattern of the homogeneous medium to large lymphoma cells with diffuse expression of many B-cell markers (CD20+, CD79a+, PAX5+, Oct2+, BOB.1+), while it lacked any T-cell markers (CD3-, CD4-, CD5-, CD7-, CD8-). Evidence of EBV infection in the tumor cells was demonstrated by EBV-LMP1 immunostaining and EBER in situ hybridization. Interestingly, the tumor cells had a TIA-1 expression but not perforin or granzyme B. Even though the genetic profiles showed dual genotype but the lymphoma cells expressed typical B-cell phenotype. Thus, we concluded this case as an EBV-positive DLBCL of the elderly with dual genotype and aberrant TIA-1 expression. By the lacking of polymorphous morphology, this is a large lymphoma-cell subtype but it does not have any clinical significance [1].

Differential diagnoses in the present case include classical Hodgkin lymphoma (CHL), lymphomatoid granulomatosis (LYG) grade 3, DLBCL associated with chronic inflammation, and DLBCL, not otherwise specified (NOS). Since this case had a typical DLBCL morphology, no inflammatory background, Reed-Sternberg-like cell, or large anaplastic-looking cell, was noted, and together with the diffuse expression of CD20, CD79a, Oct2, and BOB.1, CHL was then excluded, although there was only partial expression of CD45 [1]. One cannot rely on expression of CD30 in this situation because CD30 expression can be 
observed in some cases of DLBCL. Distinction from CHL can also be made by the large number of lymphoma cells with expression of CD20 or other B-cell markers, usually greater than $50 \%$ of the lymphoma cells as suggested by Asano et al. [12]. LYG grade 3 is the most difficult one to be distinguished from EBV-positive DLBCL of the elderly since both share a similar morphology in terms of a large number of large B-cells, angiodestructive pattern, and association with EBV. However, this case had no polymorphous background, but did have diffuse sheets of monotonous large B-cells; thus, according to the WHO classification, the present case was not considered in the diagnostic criteria of LYG [1]. DLBCL associated with chronic inflammation is another EBV-associated DLBCL, and it may have extensive necrosis and angiocentric growth. However, the lack of a history of chronic inflammation in the left parotid area in the present case should be sufficient to exclude DLBCL associated with chronic inflammation [1, 13, 14]. DLBCL, NOS was discussed here as a differential diagnosis, but it should be emphasized that, to make the diagnosis of "DLBCL, NOS," according to the WHO classification, one needs to exclude a number of specific large B-cell lymphoma entities. Clinical information is therefore very important for an appropriate line of investigation. Even with the age of the patient ( $>50$ years), regardless of available information of any immunodeficiency or prior lymphoma, one should consider performing in situ hybridization for EBER in order to diagnose EBV-positive DLBCL of the elderly, as in the present case.

TIA-1 protein is found in the cytoplasm of both normal and neoplastic cytotoxic T-cells and NK-cells $[1,4,6]$. In the aspect of TIA-1 protein expression in B-cell derived neoplasms, Mori et al. reported a high proportion (five of nine cases) of TIA-1 protein expression in hairy cell leukemia [15]. However, expression of granzyme B and perforin was not found in these cases [15]. Felgar et al. and Kanavaros et al. reported a low proportion of Hodgkin lymphoma with TIA-1 protein expression [16, 17]. In addition, a case of pyothorax-associated lymphoma with TIA-1 protein expression was reported by Nakamichi et al. [18]. Therefore, a few cases of B-cell-derived neoplasms with TIA-1 protein expression were readily identified.

Perforin and granzyme B, the other types of cytotoxic associated protein, are expressed at the higher level in activated cytotoxic T-cells and NK-cells [19, 20]. Both of them are secreted to target cells in order to induce apoptosis [21-23]. In contrast to perforin and granzyme B, TIA-1 was not mentioned as a degranulated cytotoxic protein to target cells in the recent review literature [21-23], but it is found at the membrane of cytotoxic granules by immuno-electron microscopy technique [24]. In addition, perforin or granzyme B expression in B-cell non-Hodgkin lymphomas has never been reported. Therefore, for determination of cytotoxic property of lymphoid cells, perforin and granzyme B seem to have a higher specificity than TIA-1.

In this case, the tumor cells expressed only TIA-1, but not perforin and granzyme B; thus, the TIA-1 expression may not reflect a functional cytotoxic property. However, the cause and significance of TIA- 1 expression in this case are not known. Unfortunately, we did not have an adequate tissue for electron microscopic study to verify the existence of cytotoxic granules in the lymphoma cells. We also did not have fresh tissue for flow cytometry or cytogenetics.

We used both gel and fluorescence capillary electrophoresis for genotypic determination of the lymphoma. Fluorescence capillary electrophoresis has been documented as having a higher sensitivity for detection of lymphoma clonality than the aforementioned technique [25-27]. In our experience, some lymphoma cases with negative results by gel electrophoresis might show positive results by fluorescence capillary electrophoresis. Moreover, fluorescence capillary electrophoresis provides semiquantitative assessment to the tests. Therefore, it is possible that gel electrophoresis can produce a false-negative result in this particular case.

Theriault et al., Garcia et al., and Vergier et al. studied the IgH and TCR gene analysis in B-cells and T-cells neoplasms; bigenotypic cases of overall mature B-cell neoplasms were $10 \%$ (18/181 cases), $16 \%$ (7/43 cases), and $13 \%$ (43/316 cases), respectively, while bigenotypic DLBCL in the same studies were 13\% (5/38 cases), $17 \%$ ( $2 / 12$ cases), and $17 \%$ (19/112 cases), respectively [7, 8, 10]. Thus, by conventional techniques, bigenotypic DLBCL is not uncommon. In addition, using a single-cell microdissection (after immunohistochemistry) and singlecell combined IgH and TCR gene analysis, Vergier et al. demonstrated a case of mantle cell lymphoma of genuine dual genotype, whereas the other case of DLBCL had only $\mathrm{IgH}$ gene rearrangement where TCR gene rearrangement was found only in the microdissected T-cells $(\mathrm{CD} 3+$ or CD4+) [10]. Therefore, dual genotype does not go against the diagnosis of B-cell lymphoma in the particular case with typical B-cell phenotype. In the present case, we did not have a single-cell microdissection available to confirm whether the lymphoma cell had genuine dual genotype or not.

The cause and significance of lymphoma with dual genotype are not known. A previous study suggested that immunodeficiency state may increase possibility of lymphoma with dual genotype [28], but only a few cases were included in the study to make such a conclusion.

In conclusion, DLBCL with dual phenotype is not uncommon, but a case with aberrant expression of TIA-1 is extremely rare. After extensive search in the English literature, we found only a reported case of pyothorax- 
associated lymphoma that had dual genotype and also expressed TIA-1 protein [18], similar to our case. The cause and significance of TIA-1 expression in B-cell neoplasms should be further investigated.

\section{Follow up}

The patient's chest X-ray film revealed right upper lobe infiltration without hydrothorax. Bronchoscopy with transbronchial biopsy was then performed, yielding necrotic tissue containing a few acid-fast bacilli, diagnostic of mycobacterial infection. Therefore, the patient was treated with anti-tuberculotic drugs. For the specific lymphoma, the first cycle of R-CHOP chemotherapy was administered; however, the parotid mass and clinical symptoms were not improved. Finally, he refused to receive any more specific treatment for lymphoma and returned home to receive the medical treatment from a local hospital in his hometown.

Conflict of interest The authors declare that they have no conflict of interest.

\section{References}

1. Swerdlow HS, Campo E, Harris NL, Jaffe ES, Pileri SA, Stien H et al (2008) World Health Organization Classification of Tumours. Pathology and Genetics of Tumours of Haematopoietic and Lymphoid Tissues. IARC Press, Lyon, France

2. Intragumtornchai $\mathrm{T}$, Wannakrairoj $\mathrm{P}$, Chaimongkol B, Bhoopat $\mathrm{L}$, Lekhakula A, Thamprasit T et al (1996) Non-Hodgkin's lymphomas in Thailand. A retrospective pathologic and clinical analysis of 1391 cases. Cancer 78(8):1813-1819

3. Sukpanichnant S (2004) Analysis of 1983 cases of malignant lymphoma in Thailand according to the World Health Organization classification. Hum Pathol 35(2):224-230

4. Anderson P, Nagler-Anderson C, O'Brien C, Levine H, Watkins S, Slayter HS et al (1990) A monoclonal antibody reactive with a 15$\mathrm{kDa}$ cytoplasmic granule-associated protein defines a subpopulation of CD8+ T lymphocytes. J Immunol 144(2):574-582

5. Forch P, Valcarcel J (2001) Molecular mechanisms of gene expression regulation by the apoptosis-promoting protein TIA-1. Apoptosis 6(6):463-468

6. Boulland ML, Kanavaros P, Wechsler J, Casiraghi O, Gaulard P (1997) Cytotoxic protein expression in natural killer cell lymphomas and in alpha beta and gamma delta peripheral T-cell lymphomas. J Pathol 183(4):432-439

7. Theriault C, Galoin S, Valmary S, Selves J, Lamant L, Roda D et al (2000) PCR analysis of immunoglobulin heavy chain $(\operatorname{IgH})$ and TcR-gamma chain gene rearrangements in the diagnosis of lymphoproliferative disorders: results of a study of 525 cases. Mod Pathol 13(12):1269-1279

8. Garcia MJ, Martinez-Delgado B, Granizo JJ, Benitez J, Rivas C (2001) IgH, TCR-gamma, and TCR-beta gene rearrangement in 80 B- and T-cell non-Hodgkin's lymphomas: study of the association between proliferation and the so-called "aberrant" patterns. Diagn Mol Pathol 10(2):69-77
9. Svachova M, Tichy M (2008) PCR analysis of immunoglobulin heavy chain and TCR gene rearrangements in diagnosis of lymphoproliferative disorders on formalin-fixed, paraffinembedded tissues. Neoplasma 55(1):36-41

10. Vergier B, Dubus P, Kutschmar A, Parrens M, Ferrer J, de Mascarel A et al (2002) Combined analysis of $\mathrm{T}$ cell receptor gamma and immunoglobulin heavy chain gene rearrangements at the single-cell level in lymphomas with dual genotype. J Pathol 198(2):171-180

11. van Dongen JJ, Langerak AW, Bruggemann M, Evans PA, Hummel M, Lavender FL et al (2003) Design and standardization of PCR primers and protocols for detection of clonal immunoglobulin and T-cell receptor gene recombinations in suspect lymphoproliferations: report of the BIOMED-2 Concerted Action BMH4-CT98-3936. Leukemia 17(12):2257-2317

12. Asano N, Yamamoto K, Tamaru J, Oyama T, Ishida F, Ohshima K et al (2009) Age-related Epstein-Barr virus (EBV)-associated Bcell lymphoproliferative disorders: comparison with EBV-positive classic Hodgkin lymphoma in elderly patients. Blood 113 (12):2629-2636

13. Iuchi K, Aozasa K, Yamamoto S, Mori T, Tajima K, Minato K et al (1989) Non-Hodgkin's lymphoma of the pleural cavity developing from long-standing pyothorax. Summary of clinical and pathological findings in thirty-seven cases. Jpn J Clin Oncol 19(3):249-257

14. Cheuk W, Chan AC, Chan JK, Lau GT, Chan VN, Yiu HH (2005) Metallic implant-associated lymphoma: a distinct subgroup of large B-cell lymphoma related to pyothorax-associated lymphoma? Am J Surg Pathol 29(6):832-836

15. Mori N, Murakami YI, Shimada S, Iwamizu-Watanabe S, Yamashita Y, Hasegawa Y et al (2004) TIA-1 expression in hairy cell leukemia. Mod Pathol 17(7):840-846

16. Felgar RE, Macon WR, Kinney MC, Roberts S, Pasha T, Salhany KE (1997) TIA-1 expression in lymphoid neoplasms. Identification of subsets with cytotoxic T lymphocyte or natural killer cell differentiation. Am J Pathol 150(6):1893-1900

17. Kanavaros P, Vlychou M, Stefanaki K, Rontogianni D, Gaulard P, Pantelidaki E et al (1999) Cytotoxic protein expression in nonHodgkin's lymphomas and Hodgkin's disease. Anticancer Res 19 (2A):1209-1216

18. Nakamichi I, Takakuwa T, Tanio Y, Iuchi K, Aozasa K (2005) Pyothorax-associated lymphoma: an unusual case with both Tand B-cell genotypes. Virchows Arch 447(5):888-891

19. Griffiths GM, Mueller C (1991) Expression of perforin and granzymes in vivo: potential diagnostic markers for activated cytotoxic cells. Immunol Today 12(11):415-419

20. Salcedo TW, Azzoni L, Wolf SF, Perussia B (1993) Modulation of perforin and granzyme messenger RNA expression in human natural killer cells. J Immunol 151(5):2511-2520

21. Trapani JA, Smyth MJ (2002) Functional significance of the perforin/granzyme cell death pathway. Nat Rev Immunol 2 (10):735-747

22. Pardo J, Aguilo JI, Anel A, Martin P, Joeckel L, Borner C et al (2009) The biology of cytotoxic cell granule exocytosis pathway: granzymes have evolved to induce cell death and inflammation. Microbes Infect 11(4):452-459

23. Chavez-Galan L, Arenas-Del Angel MC, Zenteno E, Chavez R, Lascurain R (2009) Cell death mechanisms induced by cytotoxic lymphocytes. Cell Mol Immunol 6(1):15-25

24. Medley QG, Kedersha N, O'Brien S, Tian Q, Schlossman SF, Streuli M et al (1996) Characterization of GMP-17, a granule membrane protein that moves to the plasma membrane of natural killer cells following target cell recognition. Proc Natl Acad Sci USA 93(2):685-689

25. Beaubier NT, Hart AP, Bartolo C, Willman CL, Viswanatha DS (2000) Comparison of capillary electrophoresis and polyacrylamide 
gel electrophoresis for the evaluation of $\mathrm{T}$ and $\mathrm{B}$ cell clonality by polymerase chain reaction. Diagn Mol Pathol 9(3):121-131

26. Vega F, Medeiros LJ, Jones D, Abruzzo LV, Lai R, Manning J et al (2001) A novel four-color PCR assay to assess T-cell receptor gamma gene rearrangements in lymphoproliferative lesions. Am J Clin Pathol 116(1):17-24

27. Tang MB, Chong TK, Tan ES, Sun YJ, Tan SH (2008) A comparative study of polymerase chain reaction detection of clonal T-cell receptor gamma chain gene rearrangements using polyacrylamide gel electrophoresis versus fluorescence capillary electrophoresis. Ann Acad Med Singapore 37(1):27-31

28. Hollingsworth HC, Stetler-Stevenson M, Gagneten D, Kingma DW, Raffeld M, Jaffe ES (1994) Immunodeficiency-associated malignant lymphoma. Three cases showing genotypic evidence of both T- and B-cell lineages. Am J Surg Pathol 18 (11):1092-1101 